\title{
Improved artificial urinary sphincter outcomes using a transcorporal cuff placement in patients with a "fragile urethra"
}

\author{
Elaine J. Redmond ${ }^{1,2}$; Steven Tong ${ }^{2}$; Logan Zemp ${ }^{2}$; Nathan $\mathrm{Hoy}^{2}$; Keith F. Rourke ${ }^{2}$ \\ ${ }^{1}$ Tallaght University Hospital, Dublin, Ireland; ${ }^{2}$ Division of Urology, Department of Surgery, University of \\ Alberta, Edmonton, AB, Canada
}

Cite as: Can Urol Assoc J 2020 June 16; Epub ahead of print. http://dx.doi.org/10.5489/cuaj.6431

Published online June 16, 2020

$* * *$

\begin{abstract}
Introduction: The artificial urinary sphincter (AUS) is the most effective treatment option for incontinence after prostate cancer treatment. However, patients with a "fragile urethra" (defined as prior radiotherapy, previous failed AUS, or previous urethroplasty) are at increased risk of AUS failure. The aim of this study was to evaluate outcomes using standard and transcorporal cuff placement in this group of patients.
\end{abstract}

Methods: A retrospective review was performed on patients with a fragile urethra who underwent AUS insertion between 2004 and 2017. The primary outcome was the need for AUS revision. Secondary outcome measures included change in pad use, patient satisfaction, continence ( $\leq 1 \mathrm{pad} /$ day), improvement ( $\geq 50 \%$ change in pad use) and cuff erosion rates.

Results: Seventy-six patients met the criteria for inclusion, with a mean age of 71.6 years and a mean followup of 37.9 months. A total of $42.1 \%$ had prior radiotherapy, $56.6 \%$ had a history of failed AUS, and $19.7 \%$ had previous urethroplasty. Transcorporal cuff placement was performed in $31.6 \%(n=24)$. These patients had lower revision $(20.8 \%$ vs. $36.5 \%$; $\mathrm{p}=0.05)$ and erosion rates (8.3\% vs. $17.3 \% ; \mathrm{p}=0.09)$. There was no significant difference in functional outcomes such as continence $(66.7 \%$ vs. $73.1 \%$; $=0.57)$, improvement $(100 \%$ vs. $90.4 \%$; $=0.17)$, or satisfaction $(82.6 \%$ vs. $69.4 \%$; $\mathrm{p}=0.26)$, nor for 90 -day complications (4.2\% vs. $9.6 \%$; $\mathrm{p}=0.41)$.

Conclusions: AUS insertion is an effective treatment option for post-prostatectomy incontinence in the setting of a fragile urethra. Transcorporal cuff placement in this subset of patients may be recommended, as it is associated with lower revision and erosion rates compared to standard cuff placement. 


\section{Introduction}

The artificial urinary sphincter (AUS) is considered the most effective treatment option for post-prostatectomy incontinence related to sphincter weakness. Various studies have confirmed high satisfaction rates and continence associated with the procedure. ${ }^{1-3}$ However, the management of post prostatectomy incontinence in the setting of a fragile urethra (defined as prior radiotherapy, previous failed AUS or previous urethroplasty) is challenging, as these factors have been independently associated with poorer functional outcomes and higher revision rates. ${ }^{4-6}$ Several maneuverers have been described which aim to minimise the risk of failure, including cuff downsizing, ${ }^{7}$ insertion of $3.5 \mathrm{~mm}$ cuff, ${ }^{8}$ tandem cuff insertion, ${ }^{9-11}$ adjustment of the pressure regulating balloon ${ }^{12,13}$ and trans corporal cuff placement. ${ }^{4,14-17}$ In spite of this, there is a paucity of studies which evaluate these techniques specifically in the setting of a fragile urethra and very few studies provide a comparison with standard methods of AUS insertion. The aim of this study was to evaluate the functional outcomes and durability of AUS insertion using standard versus trans corporal cuff placement in patients with a fragile urethra. Our hypothesis is that using the trans corporal cuff technique will reduce revision rates without adversely affecting perioperative outcomes.

\section{Methods}

Patients with a "fragile urethra" who underwent implantation of an artificial urinary sphincter by a single surgeon between 2004 and 2017 were identified from procedural billing codes. A "fragile urethra" was defined as those with a history of radiotherapy, previous failed AUS or previous urethroplasty. A retrospective review of patient medical records was performed and AUS cuff placement technique recorded (Standard cuff placement or Transcorporal cuff placement (TC-AUS)). Other patient demographics included age, diabetes, obesity (BMI $\geq 35$ ), Charlson comorbidity index (CCI), salvage/adjuvant radiotherapy, previous AUS, previous urethroplasty and etiology of incontinence. The primary outcome was the need for AUS revision. Secondary outcomes included global patient satisfaction, change in pad use, continence (defined as requiring $\leq 1$ pad), improvement ( $\geq 50 \%$ change in pad use) and cuff erosion rates. Patient satisfaction was assessed by a global patient satisfaction questionnaire asking: "Are you satisfied with your level of urinary control (continence)"? Collected data was tabulated using Microsoft Excel (Microsoft Office 2010. Results were imported to SPSS25 (IBM Corp, Armonk, NY) for statistical analysis. Mean pad change was compared with t-tests. Patient satisfaction, continence and improvement rates were evaluated with Chisquare tests while revision and erosion rates were compared using the log-rank test. A pvalue of $<0.05$ was considered statistically significant. Ethical approval was granted by the University health ethics review board.

\section{Operative details}

As previously described, ${ }^{14}$ standard cuff placement is performed through a midline perineal incision. The bulbospongiosus is mobilised from the corpus spongiosum and proximal bulbar urethra is exposed circumferentially after which cuff size is measured. A transverse lower abdominal incision is made, followed by dissection of the space of Retzius and then creation 
of a subdartos pouch in the hemiscrotum. The pressure regulating balloon (PRB) is instilled with approximately $22 \mathrm{ml}$ and is placed in the retropubic space with subsequent placement of the urethral cuff and pump in the hemiscrotum. All patients had a $61-70 \mathrm{~cm}$ PRB placed. Once all components are connected the device is cycled to ensure proper function and absence of leaks and deactivated.

All patients with a "fragile urethra" are consented for a possible TC-AUS. However the decision is ultimately made intraoperatively where the surgeon feels dorsal dissection of the corpus spongiosum would be inappropriate due to an increased risk of urethral injury or excessive atrophy of the spongiosal tissue. As described previously, ${ }^{14}$ the initial dissection mirrors that of a standard cuff placement. Once the ventral aspect of the corpus spongiosum is exposed, an approximate $3 \mathrm{~cm}$ incision is made into the tunica albuginea of both corporal bodies on either side of the lateral aspect of the corpus spongiosum. The space of Smith is then developed to accommodate a "sail" of tunica albuginea dorsally. The urethral circumference incorporating this is measured and an appropriate sized cuff is selected and placed. The lateral walls of the tunica albuginea is closed with a running horizontal mattress for hemostasis. The wound is then irrigated and the rest of the procedure completed as in the standard cuff placement.

Patients are assessed in clinic at 6 weeks postoperatively at which point the AUS is cycled and activated. Patients are reviewed in clinic at 6 and 12 months, and annually thereafter.

\section{Results}

A total of 76 AUS devices were placed in "fragile urethras" during the study period. The mean age of the group was 71.6 \pm 6.2 years with a mean follow up 37.9 \pm 28.5 months. Incontinence etiology was characterised as post radical prostatectomy in 68 cases (89.5\%), post transurethral resection of prostate in 5 cases $(6.6 \%)$, simple prostatectomy in 2 cases (2.6\%) and post cryotherapy (with radiation) in 1 case $(1.3 \%)$. Reasons for a "fragile urethra" included prior radiotherapy (42.1\%), prior AUS (56.6\%) and previous urethroplasty (19.7\%). Of those with prior AUS the reasons for revision were progressive incontinence due to urethral atrophy $(22 / 43 ; 51.2 \%)$, cuff erosion $(17 ; 39.5 \%)$, infection $(3 ; 7.0 \%)$ and mechanical failure $(1 ; 2.3 \%)$. Transcorporal placement of the AUS was performed in $31.6 \%$ of cases (24/76). Other patient demographics are further outlined in Table 1. Patients who underwent TC-AUS were more likely to have prior urethroplasty $(50 \%$ vs $5.8 \%, \mathrm{p}<0.001)$ and reported a higher preoperative mean pad use ( 7.5 vs $5.9, \mathrm{p}=0.02)$. There were no other significant differences in baseline demographics between the two groups including duration of follow-up.

Overall outcomes and outcomes by cuff technique is demonstrated in Table 2. Implanted cuff size was larger in the transcorporal group (4.6cm vs. $4.1 \mathrm{~cm} ; \mathrm{p}<0.001)$. 90-day complications occurred in 6 patients $(7.9 \%)$ including transient retention (2), hematuria (1) and acute infection (3) which did not differ by cuff technique $(\mathrm{p}=0.41)$. Overall patient satisfaction, improvement ( $\geq 50 \%$ reduction in pad use) and continence rates following surgery were $73.6 \%, 93.4 \%$ and $71.1 \%$ respectively. There were no significant differences in 
satisfaction ( $82.6 \%$ vs. $69.4 \%$; $=0.26)$, improvement $(100 \%$ vs. $90.4 \% ; \mathrm{p}=0.17)$ or continence $(66.7 \%$ vs. $73.1 \%$; $=0.57)$ between those who had TC-AUS versus standard cuff placement. However, TC-AUS was associated with a greater change in pad use (6.5 vs.5.0; $\mathrm{p}=0.02$ ). The overall revision rate was $31.6 \%$ and cuff erosion rate was $14.5 \%$. Patients who had TC-AUS had significantly lower revision rates $(20.8 \%$ vs. $36.5 \% ; \mathrm{p}=0.05)$ and a trend towards lower erosion rates ( $8.3 \%$ vs. $17.3 \%$; $=0.09)$. The indications for revision surgery in this cohort were cuff erosion $(11 / 24 ; 45.8 \%)$, progressive incontinence due to urethral atrophy $(8 ; 33.3 \%)$, infection $(3 ; 12.5 \%)$, mechanical failure $(1 ; 4.2 \%)$ and urethral stricture at the cuff site $(1 ; 4.2 \%)$.

\section{Discussion}

Despite a number of device ${ }^{18}$ and peri-procedural modifications ${ }^{3}$ since the AUS was first introduced in the 1970's,${ }^{19}$ the risk of revision surgery due to infection, device malfunction or erosion remains high, particularly in the "fragile urethra". ${ }^{4,20}$ Several techniques have been described to enhance the success of the procedure including transcorporal positioning of the cuff. Incorporation of the corporal bodies as a means to reduce the risk of cuff erosion was first proposed by Nelson in $1986 .{ }^{21}$ Webster later described transcorporal placement of the cuff, ${ }^{15}$ a technique which has been more widely adopted in modern practice. Several papers have reported on the success of this technique; however the majority of studies have been limited by small numbers, the use of diverse population groups or lack of functional outcomes. ${ }^{4,14-17}$ To our knowledge, this is the first study to directly compare the long term functional outcomes and device durability of TC-AUS with standard cuff placement in the fragile urethra.

Our study found acceptable satisfaction, improvement and continence rates in both groups. The position of cuff placement did not appear to affect functional outcomes. There was a significant difference in the change in pad use between the groups; however this may be explained by the difference in pre-operative pad use. Both groups reported identical postoperative pad use. The effect of trans corporal cuff placement on erectile function was not assessed in our study as the vast majority of patients had severe pre-existing erectile dysfunction owing to treatment of their prostate cancer. While studies have failed to show a significant change in erectile function with trans corporal cuff placement, ${ }^{16,17}$ it is important that patients are appropriately counselled regarding the potential effect of corporal dissection on remaining erectile function. The 90-day complication rate was low in both groups and there was no increased risk of bleeding or haematoma associated with dissection of the corpora.

The increased failure rate associated with the placement of AUS in patients with a "fragile urethra" is well recognised. ${ }^{22-24}$ Radiotherapy, previous failed AUS and previous urethroplasty all have the same potential to compromise the integrity of the uretha with devastating consequences. Urethral fibrosis from radiation or previous urethral surgery increases the complexity of dissection which may compromise both the integrity and coaptive ability of the urethral tissue. Disruption of the anatomical blood supply to the urethra from previous dissection, transection or as a result of post radiotherapy microangiopathy may 
impair wound healing, limit support of the sphincter cuff and increase the risk of infection or erosion. Our study found that trans corporal cuff placement was associated with a

significantly lower revision rate and a trend towards lower erosion rates compared to standard cuff placement. This technique minimises dorsal dissection of the urethra, likely reducing the risk of dissection injury. Additionally, the inclusion of tunical tissue enhances the cuff fit by increasing the urethral girth, may prevent atrophy of the corpus spongiosum which is already deficient in this distal location and ultimately may provide a greater margin of safety against cuff erosion. Despite this more extensive surgical dissection transcorporal cuff placement did not appear to adversely impact the rate of peri-operative complications.

The most significant limitation of this study is its retrospective design. There were notable differences in baseline characteristics between the two groups in our study which reflects our inherent bias that TC-AUS placement is preferable in patients with a fragile urethra. Nevertheless, these differences appeared to favour the group who underwent standard cuff placement and therefore may have underestimated the benefit of TC-AUS. Previous attempts at a randomised controlled trial to compare TC-AUS versus standard cuff placement were unsuccessful due to inadequate enrolment. ${ }^{25}$ In light of our study and others, the possibility of a future randomised controlled trial is difficult to envisage given the ethical considerations of randomising patients with a fragile urethra to standard cuff placement.

\section{Conclusions}

Insertion of an artificial urinary sphincter in patients with a fragile urethra is associated with a higher risk of erosion and revision. Our study found lower revision and erosion rates in patients who underwent transcorporal cuff placement. Therefore we recommend transcorporal placement of the AUS cuff in these patients as this may reduce the risk of device failure without compromising functional outcome or increasing peri-operative adverse events. 


\section{References}

1. Herschorn S. The artificial urinary sphincter is the treatment of choice for postradical prostatectomy incontinence. Can Urol Assoc J. 2008; 2:536-539

2. Van der Aa F, Drake MJ, Kasyan GR, Petrolekas A, Cornu JN, Young Academic Urologists Functional Urology. The artificial urinary sphincter after a quarter of a century: a critical systematic review of its use in male non-neurogenic incontinence. Eur Urol 2013; 63:681-689

3. Ratan H, Summerton DJ, Wilson SK, Terry TR. Development and current status of the AMS 800 artificial urinary sphincter. EAU-EBU Update Series 2006; 4:117-128

4. McGready JB, McAnninch JW, Truesdale MD, et al. Artificial urinary sphincter placement and survival in compromised urethras: a comparison of virgin, radiated and reoperative cases. J Urol. 2014; 192:1756-1761

5. Peterson AC, Webster GD. Artificial urinary sphincter: lessons learned. Atlas Urol Clin. 2004; 12:265-274.

6. Kowalczyk JJ, Nelson R, Mulcahy JJ. Successful reinsertion of the artificial urinary sphincter after removal for erosion or infection. Urology. 1996; 48:906-908.

7. Saffarian A, Walsh K, Walsh IK, Stone AR. Urethral atrophy after artificial urinary sphincter placement: is cuff downsizing effective? J Urol. 2003; 169:567-9.

8. Hudak SJ, Morey AF. Impact of $3.5 \mathrm{~cm}$ artificial urinary sphincter cuff on primary and revision surgery for male stress urinary incontinence. J Urol. 2011; 186:1962-6.

9. Kowalczyk JJ, Spicer DL, Mulcahy JJ. Erosion rates of the double cuff AMS 800 artificial urinary sphincter: long-term follow-up. J. Urol. 1996; 156:1300-1.

10. Di Marco DS, Elliott DS. Tandem cuff artificial urinary sphincter as a salvage procedure following failed primary sphincter placement for the treatment of postprostatectomy incontinence. J. Urol. 2003; 170:1252-4.

11. Brito CG, Mulcahy JJ, Mitchell ME, Adams MC. Use of a double cuff AMS 800 urinary sphincter for severe stress incontinence. J. Urol. 1995; 149: 283-5.

12. Eswara JR, Chan R, Vetter JM, Lai HH, Boone TB, Brandes SB. Revision techniques after artificial urinary sphincter failure in men: results from a multicenter study. Urology, 86 (2015), pp. 176-180

13. Moses RA, Keihani S, Craig JR, Basilius J, Hotaling JM, Lenherr SM, Brant WO, Myers JB. Efficacy of Pressure Regulating Balloon Exchange in Men with Post Artificial Urinary Sphincter Persistent or Recurrent Stress Urinary Incontinence. Urology. 2019; 123:252-7.

14. Hoy NY, Rourke KF. Artificial urinary sphincter outcomes in the "fragile urethra". Urology. 2015;86(3):618-24.

15. Guralnick ML, Webster GD. Transcorporal insertion of AMS800 artificial urinary sphincter. Atlas of the Urologic Clinics of North America. 2003 Apr 1;11(1):83-7.

16. Le Long E, Rebibo JD, Nouhaud FX, Grise P. Transcorporal artificial urinary sphincter in radiated and non - radiated compromised urethra. Assessment with a minimum 2-year follow-up. Int Braz J Urol. 2016;42(3):494-500.

17. Wiedemann L, Cornu JN, Haab E, Peyrat L, Beley S, Cathelineau X, et al. Transcorporal artificial urinary sphincter implantation as a salvage surgical procedure for challenging cases of male stress urinary incontinence: surgical technique and functional outcomes in a contemporary series. BJU Int. 2013; 112:1163-8. 
18. Light JK, Reynolds JC. Impact of the new cuff design on reliability of the AS800 artificial urinary sphincter. J Urol. 1992; 147: 609-611

19. Scott FB, Bradley WE, Timm GW. Treatment of urinary incontinence by implantable prosthetic sphincter. Urology 1973:252-259.

20. Linder BJ, Rivera ME, Ziegelmann MJ, Elliott DS. Long-term Outcomes Following Artificial Urinary Sphincter Placement: An Analysis of 1082 Cases at Mayo Clinic. Urology 2015;86(3):602-607

21. Nelson RP. Incorporation of corpora cavernosa in bulbous urethral artificial urinary sphincter. J Urol. 1986;136(1):102-3.

22. Brant WO, Erickson BA, Elliott SP, et al. Risk factors for erosion of artificial urinary sphincters: a multicenter prospective study. Urology 2014; 84:934-938

23. Hird AE, Radomski SB. Artificial urinary sphincter erosion after radical prostatectomy in patients treated with and without radiation. Can Urol Assoc J 2015: E354-E358

24. Martins FE, Boyd SD. Post-operative risk factors associated with artificial urinary sphincter infection-erosion. Br J Urol 1995; 75:354-358

25. ClinicalTrials. [Internet]. Bethesda (MD): National Library of Medicine (US). 2000 Feb 29. Identifier NCT02591381, Transcorporal Versus Standard Artificial Urinary Sphincter Placement (TC vs ST AUS); 2015 Oct 3 [cited 2019 Jul 30]. Available from: https://clinicaltrials.gov/ct2/show/NCT02591381 
Figures and Tables

\begin{tabular}{|l|c|c|c|c|}
\hline Table 1. Patient demographics & $\begin{array}{c}\text { Overall } \\
\text { (n=76) }\end{array}$ & $\begin{array}{c}\text { Transcorporal } \\
\mathbf{c u f f} \\
(\mathbf{n = 2 4 )}\end{array}$ & $\begin{array}{c}\text { Standard } \\
\mathbf{c u f f} \\
(\mathbf{n = 5 2})\end{array}$ & $\mathbf{p}$ \\
\hline Age (years) & $71.6 \pm 6.2$ & 72.2 & 71.3 & 0.57 \\
\hline Mean Charlson comorbidity index & $2.4 \pm 0.5$ & 2.9 & 2.2 & 0.17 \\
\hline BMI $\geq 35$ & $14(18.4 \%)$ & $5(20.8 \%)$ & $9(17.4 \%)$ & 0.76 \\
\hline Diabetes & $17(22.4 \%)$ & $4(16.7 \%)$ & $\begin{array}{c}13 \\
(25.0 \%)\end{array}$ & 0.56 \\
\hline Previous radiotherapy & $32(42.1 \%)$ & $9(37.5 \%)$ & $\begin{array}{c}23 \\
(44.2 \%)\end{array}$ & 0.63 \\
\hline Previous vesicourethral stenosis & $21(27.6 \%)$ & $10(41.7 \%)$ & $\begin{array}{c}11 \\
(21.2 \%)\end{array}$ & 0.10 \\
\hline Previous artificial urinary sphincter & $43(56.6 \%)$ & $13(54.2 \%)$ & $\begin{array}{c}30 \\
(57.2 \%)\end{array}$ & 0.81 \\
\hline Previous male sling & $7(9.2 \%)$ & $2(8.3 \%)$ & $5(9.6 \%)$ & 0.86 \\
\hline Previous urethroplasty & $15(19.7 \%)$ & $12(50.0 \%)$ & $3(5.8 \%)$ & $<0.001$ \\
\hline Transecting anastomotic & $10 / 15$ & $9 / 12$ & $1 / 3$ & \\
\hline Non-transecting anastomotic & $4 / 15$ & $3 / 12$ & $1 / 3$ & \\
\hline $\begin{array}{l}\text { Penile urethroplasty with } \\
\text { fasciocutaneous flap }\end{array}$ & $1 / 15$ & 0 & $1 / 3$ & \\
\hline
\end{tabular}

BMI: body mass index.

Table 2. Comparison of outcomes in patients receiving AUS with transcorporal and standard cuff placement

\begin{tabular}{|c|c|c|c|c|}
\hline Outcome & $\begin{array}{c}\text { Overall } \\
(n=76)\end{array}$ & $\begin{array}{c}\text { Transcorporal } \\
\text { cuff } \\
(n=24)(\%)\end{array}$ & $\begin{array}{l}\text { Standard cuff } \\
(n=52)(\%)\end{array}$ & $\mathbf{p}$ \\
\hline Cuff size & $\begin{array}{c}4.3 \pm 0.4 \mathrm{~cm} \\
(3.5-5.5)\end{array}$ & $\begin{array}{c}4.6 \pm 0.4 \mathrm{~cm} \\
(4-5.5)\end{array}$ & $\begin{array}{c}4.1 \pm 0.3 \mathrm{~cm} \\
(3.5-5)\end{array}$ & $<0.001$ \\
\hline 90-day complication & $6(7.9 \%)$ & $1(4.2 \%)$ & $5(9.6 \%)$ & 0.41 \\
\hline Followup (months) & 37.9 & 42.0 & 36.9 & 0.41 \\
\hline Patient satisfaction & $\begin{array}{c}53 / 72 \\
(73.6 \%)\end{array}$ & $19 / 23(82.6 \%)$ & $34 / 49(69.4 \%)$ & 0.26 \\
\hline Continence rate & $54(71.1 \%)$ & $16(66.7 \%)$ & $38(73.1 \%)$ & 0.57 \\
\hline Improvement rate & $71(93.4 \%)$ & $24(100 \%)$ & $47(90.4 \%)$ & 0.17 \\
\hline Preoperative pad use & $6.4 \pm 2.6$ & 7.5 & 5.9 & 0.02 \\
\hline Postoperative pad use & $0.9 \pm 1.1$ & 0.9 & 0.9 & 0.95 \\
\hline Mean change in pad use & $5.5 \pm 2.6$ & 6.5 & 5 & 0.02 \\
\hline Revision rate & $24(31.6 \%)$ & $5(20.8 \%)$ & $19(36.5 \%)$ & $\begin{array}{c}\mathbf{0 . 0 5}(\log \\
\text { rank) }\end{array}$ \\
\hline Erosion rate & $11(14.5 \%)$ & $2(8.3 \%)$ & $9(17.3 \%)$ & $\begin{array}{c}0.09(\log \\
\text { rank) }\end{array}$ \\
\hline
\end{tabular}


